УДК 577.113:582.29:58.056

\title{
ГОДОВАЯ ДИНАМИКА СОДЕРЖАНИЯ УСНИНОВОЙ КИСЛОТЫ В ТАЛЛОМАХ ЛИШАЙНИКОВ РОДОВ CLADONIA И FLAVOCETRARIA, ПРОИЗРАСТАЮЩИХ В ЦЕНТРАЛЬНОЙ ЯКУТИИ
}

\author{
() И.А. Прокопьев ${ }^{1^{*}}$, А.А. Шеин ${ }^{1}$, Г.В. Филиппова ${ }^{1}$, Э.В. Филиппов ${ }^{1}$, М.М. Шашурин ${ }^{1}$, Н.П. Гладкина ${ }^{2}$ \\ ${ }^{1}$ Институт биологических проблем криолитозоны СО РАН, пр. Ленина, 41, \\ Якутск, 677980 (Россия), e-mail: llya.a.prokopiev@gmail.com \\ ${ }^{2}$ Северо-восточный фредеральный университет им. М.К. Аммосова, \\ ул. Белинского, 58, Якутск, 677000 (Россия)
}

\begin{abstract}
Изучена годовая динамика содержания усниновой кислоты, наиболее часто встречаемого и хорошо изученного представителя лишайниковых веществ, в талломах Cladonia stellaris, Cladonia arbuscula и Flavocetraria cucullata, произрастающих в сосново-шикшево-бруснично-лишайниковом лесу, расположенном в окрестностях Якутска. Определение содержания усниновой кислоты в талломах изученных лишайников методом высокоэффективной жидкостной хроматографии показало, что наибольшее содержание усниновой кислоты (1,6-1,7\% от сухой массы) характерно для лишайников, отобранных в третьей декаде июня, а наименьшее $(0,7-0,8 \%$ от сухой массы) - в декабре. При сопоставлении мониторинговых данных температуры воздуха на поверхности почвы в месте отбора проб и содержания усниновой кислоты в талломах лишайников была выявлена прямая положительная корреляция - C. stellaris ( $\mathrm{r}=0,88$; $\mathrm{p}<0,01)$, C. arbuscula $(\mathrm{r}=0,81 ; \mathrm{p}<0,01)$ и $F$. cucullata $(\mathrm{r}=0,68 ; \mathrm{p}=0,01)$, что подтверждает важную роль температурного фактора при биосинтезе данного вторичного метаболита. В целом показано, что для выделения усниновой кислоты из изученных кустистых лишайников, произрастающих в условиях Центральной Якутии (резко-континентальный климат, многолетнемерзлые грунты), оптимальным периодом сбора является начало лета.

Ключевые слова: лишайники, усниновая кислота, годовая динамика, температура, Центральная Якутия.
\end{abstract}

\section{Введение}

Лишайниковые вещества, объединяемые термином «лишайниковые кислоты», представляют собой группу природных соединений, которые не встречаются у других групп организмов. Всего известно порядка 500 соединений лишайниковых веществ, из которых наиболее часто встречаемым в талломах лишайников и хорошо изученным является усниновая кислота [1-3].

Известно, что усниновая кислота обладает как противовоспалительным действием, так и выражен-

Прокопьев Илья Андреевич - старший научный сотрудник, кандидат биологических наук, e-mail: ilya.a.prokopiev@gmail.com

Шеин Алексей Анатольевич - старший научный сотрудник, кандидат биологических наук, e-mail:bg98saa@yandex.ru

Филиппова Галина Валерьевна - старший научный сотрудник, кандидат биологических наук, e-mail: nureeva@yandex.ru

Филиппов Эдуард Васильевич - старший научный сотрудник, кандидат биологических наук, e-mail:Edy73@mail.ru

Шашурин Михаил Михайлович - научный сотрудник, кандидат биологических наук, e-mail: inwertaza@mail.ru Гладкина Наталия Павловна - студентка, e-mail: gladkina93@mail.ru ным бактерицидным в отношении грамположительных микроорганизмов и микобактерий, включая штаммы, устойчивые к антибиотикам [4, 5]. Помимо антибактериальной активности усниновая кислота обладает антипролиферативным и цитотоксическим свойствами, что позволяет рассматривать ее в качестве перспективного противоопухолевого соединения [6].

Территория Якутии обладает значительными запасами природного лишайникового сырья, что обусловливает высокий потенциал развития биотехнологического производства. В настоящее время в Якутии на основе лишайников рода кладония на-

\footnotetext{
* Автор, с которым следует вести переписку.
} 
лажено производство ряда пищевых биологически активных добавок («Ягель», «Ягель детокс» и т.д.) [7, 8].

Цель работы - изучить годовую динамику содержания усниновой кислоты в талломах лишайников Cladonia stellaris, Cladonia arbuscula и Flavocetraria cucullata, произрастающих в условиях Центральной Якутии.

\section{Экспериментальная часть}

В качестве объектов исследования были выбраны эпигейные кустистые лишайники, относящиеся к семействам Cladoniaceae (Кладония звездчатая - Cladonia stellaris (Opiz) Pouzar \& Vězda, Кладония лесная - Cladonia arbuscula s. lat.) и Parmeliaceae (Цетрария клубочковая - Flavocetraria cucullata (Bellardi) Kärnefelt \& Thell), талломы которых содержат усниновую кислоту и достаточно широко распространены в бореальных лесах Восточной Сибири [9].

Отбор образцов лишайников проводился в течение 2014-2015 гг. в третьей декаде каждого месяца на участке площадью 20 м² в сосново-шикшево-бруснично-лишайниковом лесу, расположенном в окрестностях г. Якутска (61 55 '22.30" с.ш., 129³2'5.79" в.д.).

Мониторинг температуры воздуха на поверхности почвы в месте отбора проб лишайников проводился с помощью регистраторов температуры ТР-2 «ООО Инженерные технологии» (Россия), позволяющих фиксировать температуру с интервалом измерения 2 ч.

Для определения содержания усниновой кислоты в лишайниках использовали только верхние молодые части воздушно-сухих талломов длиной не более 1,0 см. Измельченную пробу исследуемого образца навеской 0,1 г экстрагировали 10 мл ацетонитрила при постоянном перемешивании в течение 24 ч при температуре $20-25^{\circ} \mathrm{C}$. Полученный экстракт пропускали через мембранный фильтр с диаметром пор 0,20 мкм и проводили его анализ методом ВЭЖХ на микроколоночном хроматографе Милихром А-02 фирмы «ЭкоНова» (Россия) с последующей компьютерной обработкой результатов исследования программой МультиХром для Windows.

Разделение проводили на обращенно-фазовой колонке ProntoSIL 120-5-C18 AQ размером 2×75 мм. В качестве подвижной фазы «А» использовали 0,1\% водный раствор уксусной кислоты, «В»- ацетонитрил, градиентный режим элюирования с возрастанием доли «В» от 10 до $50 \%$ в течении 5 мин и от 50 до $100 \%$ - в течение 20 мин при скорости потока 100 мкл/мин и температуре колонки $40{ }^{\circ} \mathrm{C}$. Объем вносимой пробы - 4 мкл. Детектирование осуществляли с помощью сканирующего УФ-спектрофотометрического детектора при длинах волн 230, 240, 260 и 280 нм. Длина волны 230 нм использовалась в качестве опорной и аналитической, так как на нее приходится максимум поглощения усниновой кислоты.

В качестве стандарта использовали усниновую кислоту производства Sigma-Aldrich. Идентификацию усниновой кислоты в исследуемых образцах проводили путем сопоставления времен удерживания и спектральных отношений полученных пиков со стандартом.

Все аналитические измерения были выполнены в трех биологических и аналитических повторностях. Результаты экспериментов представлены в виде средней арифметической величины и ее стандартной ошибки. Для установления статистической взаимосвязи между параметрами использовали коэффициент корреляции Пирсона. Расчет проводился с помощью пакета AnalystSoft, StatPlus - программа статистического анализа, v.2007.

\section{Обсуждение результатов}

Климат Центральной Якутии характеризуется резкой континентальностью, которая проявляется в длинной, холодной, малоснежной зиме (октябрь - апрель) и коротком, жарком засушливом лете. Вследствие низких зимних и высоких летних температур годовые амплитуды в Центральной Якутии достигают рекордных значений, как нигде на земном шаре. Средние амплитуды в Якутске равны $62{ }^{\circ} \mathrm{C}$, абсолютные $100{ }^{\circ} \mathrm{C}$ и больше. Кроме того, резкая континентальность климата Центральной Якутии проявляется в высокой амплитуде суточных колебаний температуры, особенно в летние месяцы, например в Якутске в июле среднесуточные амплитуды составляют порядка $11-14{ }^{\circ} \mathrm{C}[10]$.

Известно, что усниновая кислота является оптически активным соединением, существующим в виде $(+)$ и (-) энантиомерных форм (рис. 1). По литературным данным основным энантиомером усниновой кислоты в лишайниках C. stellaris и F. cucullata является (-)-форма, а в C. arbuscula-(+) [11]. 
Считается, что сезонные изменения скорости биосинтеза усниновой кислоты в лишайниках тесно связаны с колебанием температуры, влажности и освещенности [12]. Например, отмечено, что наиболее активный биосинтез усниновой кислоты протекает при температурах от +1 до $+12{ }^{\circ} \mathrm{C}$ [12-14].

Мониторинг температуры на поверхности почвы в местах отбора лишайников показал, что наиболее высокие температуры наблюдалась в течение лета с максимумом в июле $-+18,4{ }^{\circ} \mathrm{C}$ (на поверхности почвы), низкие - в течение зимы с минимумом в декабре $--27,0^{\circ} \mathrm{C}$ (на поверхности почвы под слоем снега 20 см, рис. 2).

Наиболее высокое содержание усниновой кислоты наблюдалось в «теплый» период года (с мая по сентябрь) и находилось в диапазоне $1,1-1,7 \%$ от сухой массы для всех изученных видов лишайников (рис. 2). Максимальное содержание усниновой кислоты (1,6-1,7\% от сухой массы) в талломах всех изученных видов лишайников отмечалось в конце июня, что может быть связано с характерной для Центральной Якутии максимальной продолжительностью светового периода суток (белые ночи) в начале лета.

В первой половине зимнего периода (октябрь - декабрь), наблюдалось резкое снижение с 1,3 до 0,7\% от сухой массы содержания усниновой кислоты в талломах всех изученных видов лишайниках. Минимальное содержание усниновой кислоты обусловлено снижением в декабре температуры поверхности почвы под толщей снега до $-30{ }^{\circ} \mathrm{C}$, и связано с общим замедлением метаболических процессов. Со второй половины зимы (январь - апрель), наблюдалась тенденция к повышению содержания усниновой кислоты в диапазоне 0,9-1,1, 0,8-1,2 и 1,0-1,3\% от сухой массы для лишайников C. stellaris, C. arbuscula и $F$. cucullata соответственно. Наибольшее содержание усниновой кислоты, в данный период, отмечено в марте и апреле, что обусловлено повышением температуры поверхности почвы от $-24{ }^{\circ} \mathrm{C}$ до $-8{ }^{\circ} \mathrm{C}$ под слоем снега, что, повидимому, способствовало активации метаболических процессов в талломах лишайников $[15,16]$.

При сопоставлении данных температуры воздуха на поверхности почвы и содержания усниновой кислоты в лишайниках была выявлена прямая корреляция - C. stellaris $(\mathrm{r}=0,88 ; \mathrm{p}<0,01)$, C. arbuscula $(\mathrm{r}=0,81 ; \mathrm{p}<0,01)$ и $F$. cucullata $(\mathrm{r}=0,68 ; \mathrm{p}=0,01)$, что подтверждает важную роль температурного фактора при биосинтезе данного вторичного метаболита.

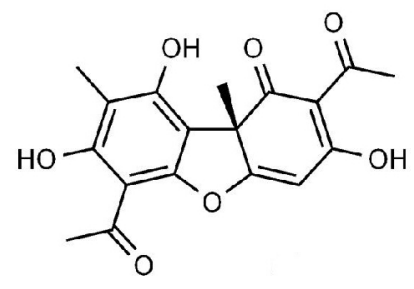

A<smiles>CC(=O)C1=C(O)C=C2Oc3c(C(C)=O)c(O)c(C)c(O)c3C(=O)[C@]2(C)C1=O</smiles>

Б

Рис. 1. Структурные формулы энантиомеров усниновой кислоты, (+) - (А) и (-) - (Б)

Рис. 2. Годовая динамика изменения температуры поверхности почвы и накопления усниновой кислоты в лишайниках, произрастающих в Центральной Якутии

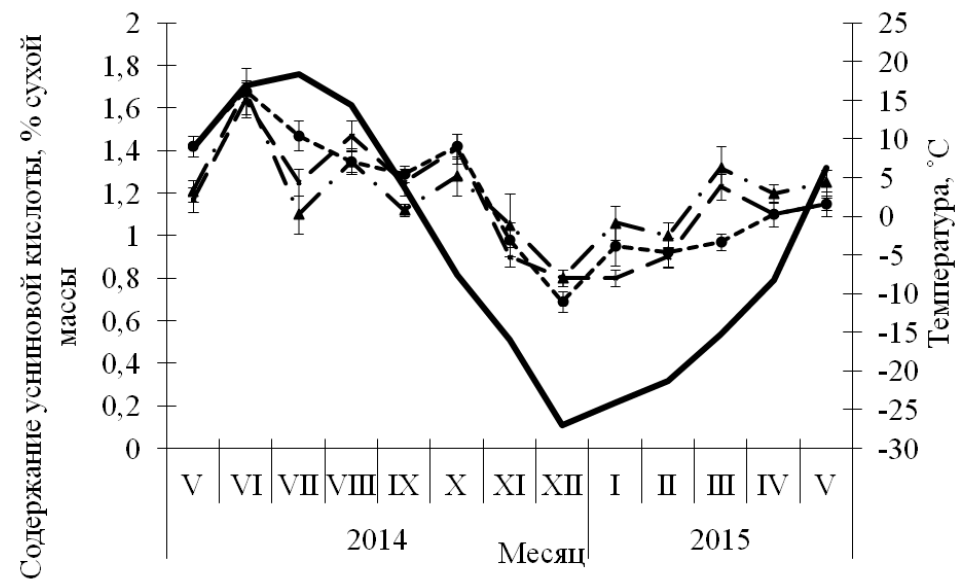

$\begin{array}{ll}- \text { - Cladonia stellaris } & - \text { Cladonia arbuscula } \\ \longrightarrow \text { - Flavocetraria cucullata } & - \text { Температура }\end{array}$ 
Сопоставление собственных данных по годовой динамике содержания усниновой кислоты в лишайниках с результатами других авторов показало, что в условиях Центральной Якутии (резкоконтинентальный климат, многолетнемерзлые грунты, белые ночи в летний период) наибольшее содержание усниновой кислоты отмечено в начале лета (июнь), в то время как в других регионах (на примере Cladonia mitis, Cladonia stellaris, Flavocetraria nivalis) - весной [12, 13, 17, 18].

\section{Bыводы}

Изучена годовая динамика содержания усниновой кислоты в талломах лишайников Cladonia stellaris, Cladonia arbuscula и Flavocetraria cucullata, произрастающих в условиях Центральной Якутии. Наибольшее содержание усниновой кислоты в лишайниках наблюдалось в июне (1,6-1,7\% от сухой массы), а наименьшее $(0,7-0,8 \%$ от сухой массы) - в декабре. Таким образом, оптимальным периодом сбора кустистых лишайников в данном регионе в целях выделения из них усниновой кислоты является начало лета.

Установлена прямая статистическая взаимосвязь между содержанием усниновой кислоты в изученных кустистых лишайниках и температурой воздуха на поверхности почвы.

\section{Список литературы}

1. Равинская А.П. Лишайниковые кислоты и их биологическая роль // Новости систематики низших растений. 1984. Т. 21. С. $160-179$.

2. Шапиро И.А. Загадки растения сфинкса. Лишайники и экологически мониторинг. Л., 1991. 82 с.

3. Дембицкий В.М., Толстиков Г.А. Органические метаболиты лишайников. Новосибирск, 2005. 135 с.

4. Lauterwein M., Oethinger M., Belsner K., Peters T., Marre R. In vitro activities of the lichen secondary metabolites vulpinic acid, (+)-usnic acid, and (-)-usnic acid against aerobic and anaerobic microorganisms // Antimicrobial Agents and Chemotherapy. 1995. Vol. 39. Pp. 2541-2543.

5. Cocchietto M., Skert N., Nimis P.L., Sava G. A review on usnic acid, an interesting natural compound // Naturwissenschaften. 2002. Vol. 89. Pp. 137-146.

6. Stanojkovic T. Investigations of Lichen Secondary Metabolites with Potential Anticancer Activity // Lichen Secondary Metabolites: Bioactive Properties and Pharmaceutical Potential. New-York ; London, 2015. Pp. 81-104

7. Кершенгольц Б.М., Журавская А.Н., Хлебный Е.С., Шеин А.А., Филиппова Г.В., Шашурин М.М., Аньшакова В.В. Биопрепараты из природного арктического биосырья в сохранении здоровья населения в условиях изменений климата (обзор) // Экология человека. 2010. № 3. С. 8-15.

8. Аньшакова В.В. Биотехнологическая механохимическая переработка лишайников рода Cladonia. M., 2013. $116 \mathrm{c}$.

9. Рассадина К.А. О сырье для препарата Бинан (натриевая соль усниновой кислоты) // Новый антибиотик бинан или натриевая соль усниновой кислоты. М.; Л., 1957. 224 с.

10. Гаврилова М.К. Климат Центральной Якутии. Якутск, 1962. 52 с.

11. Моисеева Е.Н. Биохимические свойства лишайников и их практическое значение. Л., 1961. 82 с.

12. Равинская А.П., Вайнштейн Е.А. Влияние некоторых экологических факторов на содержание лишайниковых веществ // Экология. 1975. №3. С. 82-85.

13. Taguchi H., Sankawa U., Shibata S. Biosynthesis of natural products. VII. Biosynthesis of usnic acid in lichens. Seasonal variation observed in usnic acid biosynthesis // Chem. Pharm. Bull. 1969. Vol. 17. Pp. 2061-2064.

14. Hamada N. Environmental factors affecting the content of usnic acid in the lichen mycobiont of Ramalina siliquosa // The Bryologist. 1991. Vol. 94. Pp. 57-59.

15. Вайнштейн Е.А. Некоторые вопросы физиологии лишайников. І. Дыхание // Ботанический журнал. 1972. №7. C. $832-840$.

16. Вайнштейн Е.А. Некоторые вопросы физиологии лишайников. II. Фотосинтез // Ботанический журнал. 1973. №3. C. 454-464.

17. BeGora M.D., Fahselt D. Usnic acid and atranorin concentrations in lichens in relation to bands of UV irradiance // Bryologist. 2001. Vol. 104. Pp. 134-140.

18. Bjerke J. W., Elvebakk A., Domırnguez E., Dahlback A. Seasonal trends in usnic acid concentrations of Arctic, alpine and Patagonian populations of the lichen Flavocetraria nivalis // Phytochemistry. 2005. Vol. 66. Pp. 337-344.

Поступило в редакиию 4 июня 2015 г.

После переработки 7 июля 2015 г. 
Prokopiev I.A. ${ }^{1 *}$, Shein A.A. ${ }^{l}$, Filippova G.V. ${ }^{1}$, Filippov E.V. ${ }^{l}$, Shashurin M.M. ${ }^{l}$, Gladkina N.P. ${ }^{2}$ ANNUAL DYNAMIC OF USNIC ACID CONTENT IN LICHENS GENERA CLADONIA AND FLAVOCETRARIA GROWING IN CENTRAL YAKUTIA

${ }^{1}$ Institute for Biological Problems of Cryolithozone SB RAS, Lenina, 41, Yakutsk 677980 (Russia),

e-mail: Ilya.a.prokopiev@gmail.com

${ }^{2}$ North-Eastern Federal University, Belinskogo, 58, Yakutsk, 677000 (Russia)

Annual dynamics of the content of usnic acid, the most frequently encountered and well-studied representative of lichen substances thalli Cladonia stellaris, Cladonia arbuscula and Flavocetraria cucullata, growing in pine- crowberry-cowberrylichen forest, located in the vicinity of Yakutsk was studied. Determination of usnic acid in lichen thalli analyze by high performance liquid chromatography showed that the highest content of usnic acid $(1,6-1, .7 \%$ of dry weight) is typical for lichens, collected in the June, and the lowest $(0,7-0,8 \%$ of dry weight) - December. A comparison of monitoring data of temperature on the soil surface and content of usnic acid in lichen thalli were found a direct positive correlation - C. stellaris $(\mathrm{r}=0,88$; $\mathrm{p}<0.01)$, C. arbuscula $(\mathrm{r}=0,81 ; \mathrm{p}<0,01)$ and $F$. cucullata $(\mathrm{r}=0,68 ; \mathrm{p}=0,01)$, which confirms the important role of the temperature factor in the biosynthesis of a secondary metabolite. The generally show that the best period of the studied lichens collection growing in the conditions of Central Yakutia (sharply continental climate, permafrost) for isolate usnic acid is the beginning of the summer.

Keywords: lichens, usnic acid, annual dynamic, temperature, Central Yakutia.

\section{References}

1. Ravinskaia A.P. Novosti sistematiki nizshikh rastenii, 1984, vol. 21, pp. 160-179. (in Russ.).

2. Shapiro I.A. Zagadki rasteniia sfinksa. Lishainiki i ekologicheski monitoring. [Riddles of the Sphinx plant. Lichens and environmental monitoring]. Leningrad, 1991, 82 p. (in Russ.).

3. Dembitskii V.M., Tolstikov G.A. Organicheskie metabolity lishainikov. [Organic metabolites of lichens]. Novosibirsk, 2005, 135 p. (in Russ.).

4. Lauterwein M., Oethinger M., Belsner K., Peters T., Marre R. Antimicrobial Agents and Chemotherapy, 1995, vol. 39, pp. 2541-2543.

5. Cocchietto M., Skert N., Nimis P.L., Sava G. Naturwissenschaften, 2002, vol. 89, pp. 137-146.

6. Stanojkovic T. Lichen Secondary Metabolites: Bioactive Properties and Pharmaceutical Potential. New-York; London, 2015. Pp. 81-104

7. Kershengol'ts B.M., Zhuravskaia A.N., Khlebnyi E.S., Shein A.A., Filippova G.V., Shashurin M.M., An'shakova V.V. Ekologiia cheloveka, 2010, no. 3, pp. 8-15. (in Russ.).

8. An'shakova V.V. Biotekhnologicheskaia mekhanokhimicheskaia pererabotka lishainikov roda Cladonia. [Biotechnological mechanochemical processing lichens genus Cladonia]. Moscow, 2013, 116 p. (in Russ.).

9. Rassadina K.A. Novyi antibiotik binan ili natrievaia sol' usninovoi kisloty. [New antibiotic Bean or usnic acid sodium salt]. Moscow, Leningrad, 1957, 224 p. (in Russ.).

10. Gavrilova M.K. Klimat Tsentral'noi Iakutii. [Climate Central Yakutia]. Yakutsk, 1962, 52 p. (in Russ.).

11. Moiseeva E.N. Biokhimicheskie svoistva lishainikov i ikh prakticheskoe znachenie. [Biochemical properties of lichens and their practical significance]. Leningrad, 1961, 82 p. (in Russ.).

12. Ravinskaia A.P., Vainshtein E.A. Ekologiia, 1975, no. 3, pp. 82-85. (in Russ.).

13. Taguchi H., Sankawa U., Shibata S. Chem. Pharm. Bull., 1969, vol. 17, pp. 2061-2064.

14. Hamada N. The Bryologist, 1991, vol. 94, pp. 57-59.

15. Vainshtein E.A. Botanicheskii zhurnal, 1972, no. 7, pp. 832-840. (in Russ.).

16. Vainshtein E.A. Botanicheskii zhurnal, 1973, no. 3, pp. 454 464. (in Russ.).

17. BeGora M.D., Fahselt D. Bryologist, 2001, vol. 104, pp. 134-140.

18. Bjerke J. W., Elvebakk A., Domınnguez E., Dahlback A. Phytochemistry, 2005, vol. 66, pp. 337-344.

Received Juny 4, 2015

Revised July 7, 2015

\footnotetext{
* Corresponding author.
} 
